\title{
Depressive Risk among Italian Socioeconomically Disadvantaged Children and Adolescents during Covid-19 Pandemic: A Cross-Sectional Online \\ Survey
}

\section{Maria Serra}

University of Bari: Universita degli Studi di Bari Aldo Moro

\section{Anna Presicci}

University of Bari: Universita degli Studi di Bari Aldo Moro

\section{Luigi Quaranta}

University of Bari: Universita degli Studi di Bari Aldo Moro

Maria Rosaria Erminia Urbano

University of Bari: Universita degli Studi di Bari Aldo Moro

Lucia Marzulli

University of Bari: Universita degli Studi di Bari Aldo Moro

\section{Emilia Matera}

University of Bari: Universita degli Studi di Bari Aldo Moro

Francesco Margari

University of Bari: Universita degli Studi di Bari Aldo Moro

Lucia Margari ( $\nabla$ lucia.margari@uniba.it)

University of Bari: Universita degli Studi di Bari Aldo Moro https://orcid.org/0000-0002-9203-3373

Research article

Keywords: COVID-19, Socioeconomic disadvantage, Low-income, Children, Adolescents, Depression, Mental health

Posted Date: May 3rd, 2021

DOI: https://doi.org/10.21203/rs.3.rs-451360/v1

License: (c) (1) This work is licensed under a Creative Commons Attribution 4.0 International License. Read Full License 


\section{Abstract \\ Background}

Children and adolescents and low-income individuals are considered particularly vulnerable for mental health implications during the current COVID-19 pandemic. Depression is one of the most frequent negative emotional responses during an epidemic outbreak, mainly due to the imposed restriction of social contacts. We aimed to assess depressive symptomatology in a sample of Italian low-income minors and to determine if pandemic-related stressors and pre-existing neuropsychiatric diagnoses would behave as risk factors for depressive symptoms.

\section{Methods}

We performed a cross-sectional study during July 2020, at the end of the Italian first wave of COVID-19 pandemic. We recruited 109 Italian socioeconomically disadvantaged children and adolescents, from 7 to 17 years. We used an online survey to collect socio-demographic and clinical data and information about pandemic-related stressors, and to assess depressive symptoms with the Children's Depression Inventory 2 (CDI 2), Parent Version (Emotional Problems subscale) and Self-Report Short Form. We performed logistic regression analysis to assess the association between depressive symptoms and potential risk factors for mental health.

\section{Results}

$22 \%$ and $14 \%$ of participants showed depressive symptoms at the CDI 2 Parent Version and Self-Report, respectively. Participants coming from families experiencing a lack of basic supplies during the pandemic (34.9\%) were more expected to show depressive symptoms at CDI 2 Parent Version.

Participants with a pre-existing neuropsychiatric diagnosis (26.6\%) were more likely to exhibit depressive symptoms measured by CDI 2 Parent Version.

\section{Conclusions}

The results of our study may be representative of a particular group of frail subjects, the socioeconomically disadvantaged children and adolescents, who were more vulnerable to depressive symptoms if they suffered from a paucity of essential supplies during the pandemic or had pre-existing neurodevelopmental disorders. The promotion of educational and child-care programs and activities could be crucial in sustaining the prevention of mental distress in those frail subjects who particularly need support outside the family.

\section{Background}


The World Health Organization declared Coronavirus Disease 2019 (COVID-19) to be a pandemic on March 12th, 2020 [1]. Italy was the first European country to face this new health emergency and has been harmed, to date, by two separate waves of the pandemic (during spring and autumn 2020), with an emerging third one.

During the COVID-19 outbreak, both the pandemic and containment measures taken by the governments have profoundly impacted daily life [2-4]. Isolation, contact restriction, and economic shutdown have generated dramatic psychological, social, and economic consequences [2, 5].

Since the beginning of the pandemic, children and young people have been considered one of the frailest groups for mental health implications [6]. Among them, those belonging to low-income families are particularly vulnerable: the necessary home confinement, ordered by the government authorities, might have led to a forced interruption of temporary works of their parents, parental unemployment, and financial insecurity $[2,3,6,7]$. Moreover, basal low-income means a paucity of essential supplies in normal conditions, with evident exacerbation during pandemics, when work opportunities are lacking.

Among the containment measures, school closure has affected millions of children worldwide and has had a significant impact on children and adolescents, especially on socioeconomically disadvantaged ones $[5,6,8-10]$. The necessary shift to the home-based distance learning models has meant the absence of school routines and outdoor activities, reduced social contact, and dropping education [7, 8, $11,12]$. The potentially negative implications of similar modifications on the psychological balance of children and adolescents could be even more pronounced for those living in poverty $[7,8,11,12]$. They often do not own an electronic device or Internet connections, making homeschooling challenging to take part in $[5,6,9]$.

In Bari province, in the South of Italy, Diurnal Socio-Educational Centers (DSECs) support low-income families in the afternoon post-school period, working as semi-residential structures. The DSECs belong to the territorial social services network offering holistic support: they operate in close connection with the school, the social services, and other educational structures; ensure educational support in learning activities; enhance good personal hygiene; contribute to healthy free nutrition by giving the midday meal and a snack; provide parenting support to the children's families [13]. A few days after the school closure (March 8th, 2020, throughout Italy), on March 12th also the DSECs were closed, as determined by the civil authorities for the entire regional territory to which Bari belongs. Short-term consequences were a further reduction of social contacts and educational support besides the loss of free healthy nutrition. The socioeconomically disadvantaged families enjoying that service found themselves trying to sustain their children through their scarce resources. In this way, DSEC shutdown increased the already heavy load given by school closure.

If poverty is a well-known risk for mental health in children and adolescents, the socio-ecological impact of the pandemic could increase this pre-existing vulnerability, both in the short term and for a lifetime [2]. It is especially true for those mental health conditions, such as depression, that are more prone to environmental risk, like stressors derived from income inequality $[14,15]$. One of the research priorities 
during the current pandemic was monitoring and reporting rates of depression and other mental health problems across the general population and vulnerable groups $[2,6]$. Although lower socioeconomic conditions have been often addressed by literature as a risk factor for children's mental health during COVID-19, only a few original studies have approached this subject, to our knowledge. Findings from the early phases of the pandemic demonstrated more pronounced behavioral and anxiety problems among young children (5 years old or less) from economically disadvantaged households [16, 17]. A large crosssectional Chinese study found a higher risk for psychosocial problems in children (2-12 years old) from low-income families [18]. In the study by Alvis and colleagues, adolescents suffering from financial difficulties were more likely to develop depressive symptoms and lower belongingness [19].

To date, to the best of our knowledge, no study has assessed the impact of COVID-19 on a homogeneous sample for environmental risk for mental health represented by socioeconomic disadvantage.

This research has aimed to determine whether the COVID-19 pandemic and its containment measures were predictors of mental health problems in a vulnerable group represented by socioeconomically disadvantaged children and adolescents. We recruited a sample of unprivileged children and adolescents attending the DSECs of the Bari province in the South of Italy. We investigated depressive symptoms at the end of the first wave of the pandemic (that in Italy covered the months of March and April 2020, with a slow return to normality during May and June 2020). We assessed if pandemic-related stressors (i.e., Sars-CoV-2 infection, quarantine, food insecurity, parental unemployment, impaired access to homeschooling) and pre-existing neuropsychiatric diagnoses would behave as risk factors for depressive symptoms.

\section{Methods}

\section{Setting and Participants}

This study was a cross-sectional online survey created on Google Forms. The questionnaire was addressed to 7 to 17-year-old individuals living in the Bari province, attending a DSEC of the territory because of their socioeconomic disadvantage. The DSECs are places of social and cultural integration for 6 to 17-year-old individuals with social problems and exposed to the risk of marginalization or deviance [13]. These structures are regulated by the regional legislation [20]: only people coming from a low socioeconomic level can access, given the required certification of an Equivalent Economic Status Indicator lower than 20.000,00 Euros [13]. We applied to the 48 DSECs of the Bari province by a telephone call and an invitation letter by email, requesting their availability to participate. We sent the survey's link to the managers of the 19 DSECs who declared themselves available. The educational team of each DSEC proposed, explained, and transmitted the survey to the parents of children and adolescents enjoying the service (approximately 800 minors). Overall 109 participants took part in the study. The form was administered from July 14th to July 29th, 2020, at the end of the Italian first wave of COVID-19. We included our email addresses at the beginning of the questionnaire to facilitate any consultation. The minors filled out the survey after their parents had consented. Anonymous data were collected. 


\section{Measurements}

The online questionnaire (Table 1) assessed the point of view of both the parents and their children with questions concerning general information, variables related to COVID-19 pandemic, and depressive symptoms measured by the Children's Depression Inventory 2 (CDI 2):

\section{Parent-report:}

- Socio-demographic and clinical characteristics.

- Pandemic-related stressors.

- Depressive symptoms, assessed by the Italian version of the CDI 2, Parent Version (PV). It is a 17item questionnaire based on a 4-point Likert scale ( $0-3)$, to be completed by the parents of young people aged 7-17 years. It gives information about children's depressive symptoms, in the last two weeks, from the parental point of view. The CDI 2 PV provides two partial scores: Emotional Problems (related to dysphoric feelings and neurovegetative symptoms) and Functional Problems (related to the functional consequences on family, school, and social contacts); the total score of the questionnaire is given by the sum of the two partial scores. In this study only the Emotional Problems score was considered, as the Functional Problems score would have been highly influenced by the lack of school attendance during the summer period: indeed, 3 out of the 8 items contributing to the latter partial score explicitly refer to school. The psychometric characteristics of the Italian version of the CDI 2 PV, Emotional Problems subscale, show reliability coefficients ranging from 0.61 to 0.74 [21]. T-scores normed based on age and sex were used in the present study. Tscores $\geq 60$ were considered positive for depressive symptoms, as per the CDI 2 scoring guidelines [21].

Self-report by children and adolescents:

- Major difficulties perceived by minors, through a question developed by our research team. More than one answer was possible.

- Depressive symptoms, assessed by the CDI 2 Self-Report (S-R) Short Form (SF). It is a 12-item 3point (0-2) Likert's self-report scale, widely used for screening purposes to investigate children's depressive symptoms, in the last two weeks, from a subjective point of view. It provides a single total score. The psychometric characteristics of the Italian version of the CDI 2 S-R SF show reliability coefficients ranging from 0.68 to 0.78 [21]. The cut-off for depressive symptoms was set at T-scores $\geq 60$. 
Table 1

Questionnaire presented during the online survey

\section{Socio-demographic and clinical information (parent-report):}

1. Sex

2. Age

3. Municipality of residence

4. Attendance at a territorial Diurnal Socio-Educational Center $(\mathrm{Y} / \mathrm{N})$

5. Pre-existing neuropsychiatric diagnosis ( $\mathrm{Y} / \mathrm{N}$. If yes, which one?)

Pandemic-related stressors (parent-report):

6. Sars-CoV-2 infection (affecting the child and/or a family member) $(\mathrm{Y} / \mathrm{N})$

7. Mandatory quarantine (affecting the child and/or a family member) $(\mathrm{Y} / \mathrm{N})$

8. Impact on the parental job (no access to previous occupation? Layoff? Dismissal? No changes?)

9. Impact on the availability of basic supplies (difficulty in finding basic supplies? More material help received than before?)

10. Impact on access to homeschooling (homeschooling from the beginning? Within 1 month?

Beyond 1 month? No homeschooling at all? No homeschooling due to unavailability of devices?)

Children's Depression Inventory 2, Parent Version

Major difficulties perceived by minors (self-report):

11. "What do you think was the greatest difficulty for you to face in this period:

- Fear of getting sick or my relatives and friends getting sick?

- Not being able to go to school?

- Not being able to go to the Diurnal Socio-Educational Center?

- Concern for the work of mum and dad?

- Not having enough water or food or clothing?

- Failing to access homeschooling due to the lack of a computer or a tablet or internet connection?"

Children Depression Inventory 2, Self-Report, Short Form

\section{Statistical Analysis}

Data were analyzed using "pandas" and "statsmodels": two software libraries written for the Python programming language for data manipulation and statistical analysis. Computation results and data visualizations were collected and documented in Python Jupyter notebooks. We used descriptive statistics and frequency analysis to analyze socio-demographic data; the pandemic-related stressors; the 
major difficulties perceived by children and adolescents; the depressive symptoms. We performed logistic regression analysis to assess the association between depressive symptoms and potential risk factors for mental health (pre-existing neuropsychiatric diagnoses and the pandemic-related stressors). Statistical significance level was set at $p<0.05$.

\section{Results}

\section{Participants socio-demographic and clinical characteristics}

The sample size of our survey included 109 participants (M: $F=1.6: 1)$, from 7 to 17 years old. The median age was 12 years. The whole sample was resident in the Bari Province and attended a territorial DSEC, as requested to be recruited in the survey. Therefore, all the participants had a socioeconomic disadvantage. A pre-existing neuropsychiatric diagnosis was present in 29 subjects (26.6\%), most frequently represented by Specific Learning Disability (SLD) (12.8\%) and Attention-Deficit/Hyperactivity Disorder (ADHD) (8.3\%). Table 2 reports complete socio-demographic and clinical characteristics. 
Table 2

Sample socio-demographic and clinical characteristics

\begin{tabular}{|ll|}
\hline Variables & $\mathbf{N}(\%)$ \\
\hline Participants & 109 \\
\hline Sex & \\
\hline Male & $68(62.4 \%)$ \\
\hline Female & $41(37.6 \%)$ \\
\hline 7-12 years & \\
\hline 13-17 years & $65(59.6 \%)$ \\
\hline Pre-existing neuropsychiatric diagnoses & $44(40.4 \%)$ \\
\hline Specific Learning Disability & $14(12.8 \%)$ \\
\hline Attention Deficit/Hyperactivity Disorder & $9(8.3 \%)$ \\
\hline Speech or other Communication Disorder & $4(3.7 \%)$ \\
\hline Intellectual Disability & $3(2.7 \%)$ \\
\hline Tic or other Movement Disorder & $2(1.8 \%)$ \\
\hline Autism Spectrum Disorder & $1(0.9 \%)$ \\
\hline Mixed Specific Developmental Disorder & $1(0.9 \%)$ \\
\hline Unspecified Psychiatric Disorder & $1(0.9 \%)$ \\
\hline
\end{tabular}

\section{Pandemic-related Stressors}

Table 3 shows the parent-reported problems related to the time of the pandemic.

Only one family reported Sars-CoV-2 infection and mandatory quarantine affecting a family member different from the minor interested in the survey. About half of the families underwent negative consequences on their jobs, mainly not managing to maintain previous occupation (22\%) or being laid off (21.1\%). 2.7\% underwent dismissal. Many low-income families received some food or food vouchers (47.7\%), but one-third of the sample experienced a lack of basic supplies (34.9\%). Thirty-five people (32.1\%) started homeschooling late, mainly within one month; seven children (6.4\%) did not attend homeschooling at all. Thirty-seven families (33.9\%) declared the impossibility to start homeschooling promptly due to the unavailability of technological devices or a reliable internet connection. 
Table 3

Pandemic-related stressors

\begin{tabular}{|ll|}
\hline Variables related to COVID-19 pandemic (parent-report) & N (\%) \\
\hline Infection with Sars-CoV-2 (affecting child and/or a family member) & $1(0.9 \%)$ \\
\hline Quarantine (affecting child and/or a family member) & $1(0.9 \%)$ \\
\hline Impact on parental job & $24(22 \%)$ \\
\hline No access to previous occupation & $23(21.1 \%)$ \\
\hline Layoff & $3(2.7 \%)$ \\
\hline Impact on availability of basic supplies & $60(55 \%)$ \\
\hline Lack of basic supplies & $38(34.9 \%)$ \\
\hline Impact on access to homeschooling & $52(47.7 \%)$ \\
\hline Homeschooling from the beginning & $74(67.9 \%)$ \\
\hline Homeschooling within one month & $31(28.4 \%)$ \\
\hline Homeschooling beyond one month & $4(3.7 \%)$ \\
\hline No homeschooling & $7(6.4 \%)$ \\
\hline
\end{tabular}

\section{Major Difficulties Perceived By Minors}

Children and adolescents perceived their concern about health (either their own or that of their relatives and friends) as the major difficulty in $60.8 \%$ of the cases. More than half the sample declared that the impossibility to attend DSEC, due to its closure, was the greatest difficulty to sustain (55.7\%). Other subjective difficulties were: school closure (37.1\%), concern for the parental job (29.9\%), impaired access to homeschooling (13.4\%), living in a very small house (12.4\%), lack of basic supplies $(11.3 \%)$.

\section{Depressive Symptoms And Potential Risk Factors}


At the CDI 2 PV, Emotional Problems subscale, 24/109 (22\%) participants obtained scores in the elevated range, suggestive of typical depressive emotional symptoms (e.g., deflected mood, physical symptoms, negative self-esteem).

Those who answered the CDI 2 S-R SF were 100 minors, with 14\% obtaining elevated scores.

Detailed scores above the cut-off can be found in Table 4.

The correlations between potential risk factors for mental health and depressive symptoms were analyzed by logistic regression (Table 5). Because of insufficient data, we could not leverage all possible independent variables to compute the regression model (e.g., we had to exclude "Sars-CoV-2 infection" and "quarantine" as we reported only one positive case for both variables).

Participants coming from families experiencing a lack of basic supplies were more expected to show depressive symptoms at CDI 2 PV, Emotional Problems subscale (OR 5.042; 95\% Cl 1.314-19.346; $\mathrm{p}<$ 0.05). Moreover, participants with a pre-existing neuropsychiatric diagnosis were more likely to exhibit depressive symptoms measured by CDI 2 PV, Emotional Problems subscale (OR 3.396; 95\% Cl 1.2159.488; $p<0.05$ ). The regression model considering the self-reported depressive symptoms as dependent variables remained above our a priori cut-off for statistical significance $(p=0.35)$.

Table 4

Depressive symptoms assessed by CDI 2 (values above the cut-off, as per CDI 2 scoring guidelines)

\begin{tabular}{|ll|}
\hline Depressive symptoms & $\mathbf{N}(\%)$ \\
\hline - CDI 2 Parent Version, Emotional Problems subscale: T-scores $\geq 60$ & $24 / 109(22 \%)$ \\
\hline - T-scores 60-64 (above average) & $7(6.4 \%)$ \\
\hline - T-scores 65-69 (elevated) & $8(7.3 \%)$ \\
\hline - T-scores $\geq 70$ (very elevated) & $9(8.2 \%)$ \\
\hline CDI 2 Self-Report Short Form: T-scores $\geq 60$ & $14 / 100(14 \%)$ \\
- T-scores 60-64 (above average) & $3(3 \%)$ \\
\hline - T-scores 65-69 (elevated) & $6(6 \%)$ \\
\hline - T-scores $\geq 70$ (very elevated) & $5(5 \%)$ \\
\hline
\end{tabular}


Table 5

Logistic regression analysis of factors influencing depressive symptoms assessed by CDI 2 Parent Version, Emotional Problems subscale

\begin{tabular}{|c|c|c|c|c|c|}
\hline & \multicolumn{5}{|c|}{$\begin{array}{l}\text { Depressive Symptoms (Emotional Problems) }(T \geq 60) \text { CDI } 2 \\
\text { PV } \\
\text { (p-value: } 0.01239^{*} \text { ) }\end{array}$} \\
\hline & \multirow[t]{2}{*}{$\begin{array}{l}\text { Partial } \\
\text { regression } \\
\text { coefficient }\end{array}$} & \multirow[t]{2}{*}{$\begin{array}{l}\text { Standard } \\
\text { error }\end{array}$} & \multirow[t]{2}{*}{$\mathrm{p}$} & \multirow[t]{2}{*}{$\begin{array}{l}\text { Odds } \\
\text { Ratio } \\
\text { (OR) }\end{array}$} & \multirow{2}{*}{$\begin{array}{l}\text { OR } \\
\text { Confidence } \\
\text { Interval } \\
5 \%-95 \%\end{array}$} \\
\hline & & & & & \\
\hline $\begin{array}{l}\text { Pre-existing neuropsychiatric } \\
\text { diagnosis }\end{array}$ & 1.2225 & 0.524 & $0.020 *$ & 3.396 & $\begin{array}{l}1.215- \\
9.488\end{array}$ \\
\hline No access to previous occupation & -1.0051 & 0.738 & 0.173 & 0.366 & $\begin{array}{l}0.086- \\
1.555\end{array}$ \\
\hline Layoff & -0.4495 & 0.696 & 0.518 & 0.638 & $\begin{array}{l}0.163- \\
2.495\end{array}$ \\
\hline Lack of basic supplies & 1.6177 & 0.686 & $0.018^{*}$ & 5.042 & $\begin{array}{l}1.314- \\
19.346\end{array}$ \\
\hline $\begin{array}{l}\text { More help received (e.g., food, } \\
\text { vouchers) }\end{array}$ & -1.2613 & 0.723 & 0.081 & 0.283 & $\begin{array}{l}0.069- \\
1.169\end{array}$ \\
\hline $\begin{array}{l}\text { No homeschooling due to } \\
\text { unavailability of technological } \\
\text { devices }\end{array}$ & 0.1381 & 0.585 & 0.813 & 1.148 & $\begin{array}{l}0.365- \\
3.610\end{array}$ \\
\hline $\mathrm{N}$ & & & & & \\
\hline
\end{tabular}

\section{Discussion}

Mental health is a critical concern in the pandemic scenario. It is particularly true when considering vulnerable populations exposed to greater environmental risk, like children and adolescents from socioeconomically disadvantaged households. We studied the psychopathological impact of the COVID19 outbreak and pandemic-related stressors on a sample of Italian minors with socioeconomic disadvantage.

We measured depressive symptoms after the first wave of the COVID-19 pandemic, when mental health symptoms were expected to increase more than the previous acute phase, due to the emerging recession, according to the literature [2]. In our sample, $22 \%$ of subjects reported depressive symptoms measured by CDI 2 PV, Emotional Problems subscale. 14\% of the minors fulfilling the CDI 2 S-R SF obtained elevated scores, suggesting depressive symptoms. None of them reported a pre-existing diagnosis of a depressive disorder: we can hypothesize that depressive symptoms could have recently emerged in all subjects. It is 
known that Major Depressive Disorder (MDD) can occur more frequently in individuals with a pre-existing genetic or environmental vulnerability, like the socioeconomic disadvantage [15]. The National Institute for Mental Health estimated the prevalence of MDD, in the year 2017, in 13.3\% of American people aged 12-17 years old [22]. In 2020 depression was estimated as the fourth leading cause of illness and disability among adolescents between 15 and 19 years and fifteenth for those aged 10-14 years [23]. Depression is also one of the most frequent negative emotional responses during an epidemic outbreak $[6,24]$. Its prevalence was expected to increase during the COVID-19 pandemic, in all populations and particularly in young people, due to the imposed restriction of social contacts [6]. Several large-scale studies from China provided reports of depressive symptoms in children and adolescents of the general population during the COVID-19 outbreak [24-28]. They reported a prevalence of depressive symptoms ranging from $11.78 \%$ [28] to $43.7 \%$ [24], based on single questionnaires. Our data are in line with those reported in the recent literature about the prevalence of depressive symptoms in the current pandemic. Notably, for a subset of children and youth, the impact on the mental health of pandemic-related stressors will not be detected immediately but after some period of development [29]. Future epidemiological large-scale studies will reveal if the prevalence of MDD has actually increased among children and adolescents, as expected due to the growing environmental pandemic-related risk.

To date, to the best of our knowledge, no study had assessed the risk for mental health among socioeconomically disadvantaged children and adolescents during the COVID-19 outbreak. We found that almost half of the sample met conditions of more marked indigence during the pandemic. Nearly $50 \%$ of the households underwent worsening working conditions; $34.9 \%$ experienced a lack of essential supplies; $33.9 \%$ did not manage to access their children to homeschooling due to the absence of devices or Internet connection. Participants from families experiencing a lack of basic supplies were more expected to show depressive symptoms at CDI 2 PV. Poverty is one of the social determinants of general and mental health; additional factors introduced by the pandemic seemed to exacerbate the pre-existing vulnerability, making some poor even poorer [30]. It is known that socio-cultural and economic contexts significantly affect the prevalence of depression [31, 32]. We may consider the deficit of essential supplies as an extreme form of poverty, hitting low-income families who relied on educational institutions for providing healthy meals for their children. With the absence of this kind of help, several families were left alone in sustaining the nutrition needs of minors. Our data suggest that those who experienced a paucity of basic supplies had a higher risk to develop depressive symptoms at the end of the Italian first wave of the COVID-19 outbreak. It is possible to hypothesize that the increased environmental risk could trigger MDD in vulnerable individuals.

More than half the minors of the sample declared that the impossibility to attend DSEC, due to its closure, was the greatest difficulty to sustain. We can deduce that this kind of educational institution would be perceived as really supportive by most minors who benefit from adequate nutrition, educational support in learning activities, playgrounds for physical activities, and regular social contacts with peers and caring adults. It is clear how a perceived supportive environment could advantage the maintenance of the psychological balance in vulnerable people. 
Another relevant issue is related to our findings: $26.6 \%$ of the sample declared a pre-existing neuropsychiatric diagnosis; all but one were neurodevelopmental disorders (NDDs), mainly represented by SLD and ADHD. This high prevalence is consistent with data from the 2016 National Survey of Children's Health, where children living in lower-income households had a higher prevalence of a parentreported diagnosis of mental, behavioral, or developmental disorder than children living in higher-income families (22.1\% versus $13.9 \%$ ) [33]. There is a lack of articles on children and adolescents with NDDs during the current pandemic, apart from Autism Spectrum Disorder (ASD) and ADHD [34]. In our sample, a pre-existing NDD correlated with the occurrence of depressive symptoms measured by the CDI 2 PV, acting as a further risk factor for depressive symptoms besides the socioeconomic disadvantage. As expected, children and adolescents with pre-existing neuropsychiatric problems were more susceptible to new mental health conditions in a time of crisis, like the present pandemic scenario $[2,35,36]$. That could be explained by several stressors, like the absence of school or other daily routines, that are important coping mechanisms for young people with NDDs like ADHD and ASD, or the inability to access regular care or mental health support $[34,36,37]$. SLD and ADHD, the most frequent neuropsychiatric diagnoses of our sample, can both hurt self-esteem, self-efficacy, and psychological well-being, favoring the development of internalizing symptomatology like anxiety and depression [37,38]. We can suppose that children and adolescents with learning disorders ( $12.8 \%$ of our sample) suffered from the increased emotional distress of adapting themselves to online classes without adequate specific tools for addressing their learning needs [38, 39].

Following the literature, in our survey, the group of families who had children with pre-existing NDDs underwent a high burden of stress: they had to sustain the special educational needs of their children without any training and in the absence of external supporting networks $[34,36]$. This kind of stress, combined with the higher economic pressure hitting low-income households especially in time of crisis, raised the risk of increased domestic violence, which is considered one of the biggest threats to children's mental health $[40,41]$.

The results of our study may be exemplary of a particular group of frail subjects represented by socioeconomically disadvantaged children and adolescents. They were more vulnerable to depressive symptoms during the COVID-19 outbreak, especially if they experienced a lack of essential supplies during the pandemic or had a pre-existing neurodevelopmental diagnosis.

\section{Conclusions}

The COVID-19 pandemic appears to have increased the already elevated risk for mental health affecting socioeconomically disadvantaged children and adolescents. The experience of a lack of essential supplies during the pandemic and pre-existing neurodevelopmental diagnoses were significantly associated with the occurrence of depressive symptoms in minors with a socioeconomic disadvantage at the end of the Italian first wave of COVID-19. International politicians should carefully consider vulnerable populations like children and adolescents from low-income households, who had to suffer the consequences of economic recession and the absence of support outside the family. The promotion of 
educational and child-care programs and activities could sustain the prevention of mental distress. There is no health without health prevention.

\section{Limitations And Strengths Of The Study}

The first limitation of the research was the small sample, which makes findings more difficult to generalize. Second, given the cross-sectional nature of data, it was not feasible to use the correlations for causal inferences. Third, the response rate was scarce (13.6\%), probably due to social disadvantage itself, making the study susceptible to non-response bias. Fourth, the association between depressive symptoms and risk factors like pre-existing NDDs and paucity of essential supplies resulted only from the parent-reported CDI 2 because the self-reported data were not statistically significant. We think the main strength of our study was the assessment of the COVID-19 impact on mental health among a homogeneous vulnerable group represented by socioeconomically disadvantaged minors. The present research could have some beneficial long-term effects by identifying mechanisms (e. g., coping strategies, preventive interventions) to support vulnerable groups such as young people with low socioeconomic status. Future larger-scale studies among similar samples of vulnerable people could confirm our findings and provide new insights.

\section{Abbreviations}

COVID-19

Coronavirus Disease

DSEC

Diurnal Socio-Educational Center

CDI 2 PV

Children's Depression Inventory 2 Parent Version

CDI 2 S-R SF

Children's Depression Inventory 2 Self-Report Short Form

SLD

Specific Learning Disability

ADHD

Attention-Deficit/Hyperactivity Disorder

MDD

Major Depressive Disorder

NDD

Neurodevelopmental Disorder

ASD

Autism Spectrum Disorder

\section{Declarations}




\section{Ethics approval and consent to participate}

This study was approved by the Independent Ethical Committee of Azienda Ospedaliero-Universitaria Consorziale Policlinico di Bari, and conducted according to the recommendations of the Helsinki Declaration. The parents of all participants provided their online informed consent.

\section{Consent for publication}

Not applicable.

\section{Availability of data and materials}

The datasets used during the current study are available from the corresponding author on reasonable request.

\section{Competing interests}

The authors declare that they have no competing interests.

\section{Funding}

No funding.

\section{Authors' contributions}

MS and AP designed the study. MS and LQ analyzed the survey data. MS was a major contributor in writing the manuscript. AP, LQ, EM and FM helped in drafting the manuscript. MREU and LMarz contributed to the literature review. LMarg supervised the research. All the authors reviewed and edited the manuscript.

\section{Acknowledgments}

Not applicable.

\section{References}

1. World Health Organization: WHO announces COVID-19 outbreak a pandemic. (2020). https://www.euro.who.int/en/health-topics/health-emergencies/coronavirus-covid19/news/news/2020/3/who-announces-covid-19-outbreak-a-pandemic. Accessed 15 Apr 2021.

2. Fegert JM, Vitiello B, Plener PL, Clemens V. Challenges and burden of the Coronavirus 2019 (COVID19) pandemic for child and adolescent mental health: a narrative review to highlight clinical and research needs in the acute phase and the long return to normality. Child Adolesc Psychiatry Ment Health. 2020;14:20.

3. Witt A, Ordóñez A, Martin A, Vitiello B, Fegert JM. Child and adolescent mental health service provision and research during the Covid-19 pandemic: challenges, opportunities and a call for 
submissions. Child Adolesc Psychiatry Ment Health. 2020;14:19.

4. Rothe J, Buse J, Uhlmann A, Bluschke A, Roessner V. Changes in emotions and worries during the Covid-19 pandemic: an online-survey with children and adults with and without mental health conditions. Child Adolesc Psychiatry Ment Health. 2021;15:11.

5. Caffo E, Scandroglio F, Asta L. Debate. COVID-19 and psychological well-being of children and adolescents in Italy. Child Adolesc Ment Health. 2020;25(3):167-8.

6. Holmes EA, O'Connor RC, Perry VH, Tracey I, Wessely S, Arseneault L, et al. Multidisciplinary research priorities for the COVID-19 pandemic: a call for action for mental health science. Lancet Psychiatry. 2020;7(6):547-60.

7. Brooks SK, Webster RK, Smith LE, Woodland L, Wessely, Greenberg N, et al. The psychological impact of quarantine and how to reduce it: rapid review of the evidence. The Lancet. 2020;395:912-20.

8. Lee J. Mental health effects of school closures during COVID-19. Lancet Child Adolesc Health. 2020;4:421.

9. Van Lancker W, Parolin Z. COVID-19, school closures, and child poverty: a social crisis in the making. Lancet Public Health. 2020;5:E243-4.

10. Viner RM, Russell SJ, Croker S, Packer J, Ward J, Stansfield C, et al. School closure and management practices during coronavirus outbreaks including COVID-19: a rapid systematic review. Lancet Child Adolesc Health. 2020;4(5):P397-404.

11. Wang G, Zhang Y, Zhao J, Zhang J, Jiang F. Mitigate the effects of home confinement on children during the COVID-19 outbreak. The Lancet. 2020;395:P945-7.

12. de Winter JP, de Winter D, Bollati V, Milani GP. A safe for children through COVID-19 disaster: keeping our mind open! Eur J Pediatrics. 2020;179:1175-7.

13. Municipality of Bari. Minors: Insertion in Diurnal Socio-Educational Centers. https://www.comune.bari.it/web/egov/-/inserimento-di-minori-in-centri-socio-educativi-diurni. Accessed 14 Apr 2021.

14. Uher R, Zwicker A. Etiology in psychiatry: embracing the reality of poly-gene-environmental causation of mental illness. World Psychiatry. 2017;16:121-9.

15. Patel V, Burns JK, Dhingra M, Tarver L, Kohrt B, Lund C. Income inequality and depression: a systematic review and meta-analysis of the association and a scoping review of mechanisms. World Psychiatry. 2018;17:76-89.

16. Center for Translational Neuroscience: Why Households with Young Children Warrant Our Attention and Support during (And after) the COVID-19 Pandemic. (2020). https://medium.com/rapid-ecproject/why-households-with-young-children-warrant-our-attention-and-support-during-and-after-theb7cee9b76184. Accessed 15 Apr 2021.

17. Center for Translational Neuroscience: Flattening the Other Curve: Trends for Young Children's Mental Health Are Good for Some, but Concerning for Others. (2020). https://medium.com/rapid-ecproject/flattening-the-other-curve-7be1e574b340. Accessed 15 Apr 2021. 
18. Tso WWY, Wong RS, Tung KTS, Rao N, Fu KW, Yam JCS, et al. Vulnerability and resilience in children during the COVID-19 pandemic. Eur Child Adolesc Psychiatry. 2020. doi:10.1007/s00787-02001680-8.

19. Alvis L, Douglas R, Shook NJ, Oosterhoff B. Adolescents' Prosocial Experiences during the COVID-19 pandemic. 2020; Preprint doi:10.31234/osf.io/2s73n.

20. Puglia region, Welfare Department. Regional Regulation Jan 18th 2007.

https://pugliasociale.regione.puglia.it/c/document_library/get_file?uuid=11d576cf-c385-4b0e-9adea8aa7594866f\&groupld=10186. Accessed 14 Apr 2021.

21. Kovacs M. Children's Depression Inventory Second Edition, Handbook. Italian adaptation (curated by Camuffo M and Cerutti R). Hogrefe; 2018.

22. National Institute of Mental Health. Major depression. https://www.nimh.nih.gov/health/statistics/major-depression.shtml. Accessed 13 Apr 2021.

23. World Health Organization: Adolescent mental health. (2020). https://www.who.int/news-room/factsheets/detail/adolescent-mental-health. Accessed 13 Apr 2021.

24. Zhou SJ, Zhang LG, Wang LL, Guo ZC, Wang JQ, Chen JC, et al. Prevalence and socio-demographic correlates of psychological health problems in Chinese adolescents during the outbreak of COVID19. Eur Child Adolesc Psychiatry. 2020;29(6):749-58.

25. Duan L, Shaoa X, Wang Y, Huang Y, Miao J, Yanga X, et al. An investigation of mental health status of children and adolescents in China during the outbreak of COVID-19. J Affect Disord. 2020;275:112-8.

26. Liu Y, Yue S, Hu X, Zhu J, Wu Z, Wang JL, et al. Associations between feelings/behaviors during COVID-19 pandemic lockdown and depression/anxiety after lockdown in a sample of Chinese children and adolescents. J Affect Disord. 2021;284:98-103.

27. Xie X, Xue Q, Zhou Y, Zhu K, Liu Q, Zhang J, et al. Mental Health Status Among Children in Home Confinement During the Coronavirus Disease 2019 Outbreak in Hubei Province, China. JAMA Pediatrics. 2020;174(9):898-900.

28. Chen F, Zheng D, Liu J, Gong Y, Guan Z, Lou D. Depression and anxiety among adolescents during COVID-19: A cross-sectional study. Brain Behav Immun. 2020;88:36-8.

29. Wade M, Prime H, Browne DT. Why we need longitudinal mental health research with children and youth during (and after) the COVID-19 pandemic. Psychiatry Res. 2020;290:113143.

30. Rosenthal DM, Ucci M, Heys M, Hayward A, Lakhanpaul M. Impacts of COVID-19 on vulnerable children in temporary accommodation in the UK. Lancet Public Health. 2020;5(5):e241-2.

31. Kleinman A. Culture and depression. N Engl J Med. 2004;351(10):951-3.

32. Compton WM, Conway KP, Stinson FS, Grant BF. Changes in the prevalence of major depression and comorbid substance use disorders in the United States between 1991-1992 and 2001-2002. Am J Psychiatry. 2006;163(12):2141-7. 
33. Cree RA, Bitsko RH, Robinson LR, Holbrook JR, Danielson ML, Smith C, et al. Health Care, Family, and Community Factors Associated with Mental, Behavioral, and Developmental Disorders and Poverty Among Children Aged 2-8 Years - United States, 2016. MMWR Morb Mortal Wkly Rep. 2018;67(50):1377-83.

34. Shorey S, Lau LST, Tan JX, Ng DE, Ramkumar A. Families with children with neurodevelopmental disorders during COVID-19: a scoping review. J Pediatr Psychol 2021;jsab029.

35. Marques de Miranda D, da Silva Athanasio B, Sena Oliveira AC, Simoes-e-Silva AC. How is COVID-19 pandemic impacting mental health of children and adolescents? Int J Disaster Risk Reduction. 2020;51:101845.

36. Asbury K, Fox L, Deniz E, Code A, Toseeb U. How is COVID-19 affecting the mental health of children with special educational needs and disabilities and their families? J Autism Dev Disord. 2020;31:19.

37. Zhang J, Shuai L, Yu H, Wang Z, Qiu M, Lu L, et al. Acute stress, behavioural symptoms and mood states among school-age children with attention-deficit/hyperactive disorder during COVID-19 outbreak. Asian J Psychiatr. 2020;51:102077.

38. Cataudella S, Carta S, Mascia ML, Masala C, Petretto DR, Penna MP. Psychological aspects of students with learning disabilities in e-environments: a mini review and future research directions. Front Psychol. 2021;11:611818.

39. Patel K. Mental health implications of COVID-19 on children with disabilities. Asian J Psychiatr. 2020;54:10227.

40. Holt S, Buckley $\mathrm{H}$, Whelan S. The impact of exposure to domestic violence on children and young people: A review of the literature. Child Abuse Negl. 2008;32(8):797-810.

41. Maalla MN. Hidden scars: the impact of violence and the COVID-19 pandemic on children's mental health. Child Adolesc Psychiatry Ment Health. 2020;14:33. 